\title{
Detection of petroleum hydrocarbons in continental areas using airborne hyperspectral thermal infrared data (SEBASS)
}

\author{
Rebecca Del'Papa Moreira Scafutto ${ }^{\mathrm{a}, *}$, Caroline Lievens ${ }^{\mathrm{b}}$, Christopher Hecker ${ }^{\mathrm{b}}$, \\ Freek D. van der Meer ${ }^{\mathrm{b}}$, Carlos Roberto de Souza Filho ${ }^{\mathrm{a}}$ \\ ${ }^{a}$ University of Campinas, UNICAMP, Institute of Geosciences, PO Box 6152, 13083-855 Campinas, SP, Brazil \\ ${ }^{\mathrm{b}}$ University of Twente, Faculty of Geo-information Science and Earth Observation, Department of Earth Systems Analysis, Hengelosestraat 99,7514 AE Enschede, the \\ Netherlands
}

\section{A R T I C L E I N F O}

\section{Keywords:}

Hydrocarbon

Soil

Hyperspectral

Thermal infrared

Airborne

Mapping

Seepage

Leakage

\begin{abstract}
A B S T R A C T
Remote sensing tools have proven to be effective for direct detection of petroleum hydrocarbons (PHC) in continental areas. PHC yield diagnostic absorption features in the near, shortwave, midwave, and thermal infrared (NIR-SWIR-MWIR-TIR) ranges. Thus far, the NIR-SWIR range has been primarily exploited for remote sensing PHC detection, whereas the application of MWIR and TIR data has remained underexplored. In this work, we aim to close this gap by using the Spatially-Enhanced Broadband Array Spectrograph System (SEBASS) $(7.6-13.5 \mu \mathrm{m})$ to map PHC-impregnated soil substrates. A laboratory experiment was performed to identify the features in pure crude oil samples, in dry/wet mineral substrates, and in their physical mixtures using attenuated total reflectance (ATR) and directional-hemispherical reflectance (DHR) measurements. A similar setting was designed in an open environment and imaged by the SEBASS sensor. Close-range spectroscopy indicated that PHC features between 7 and $15 \mu \mathrm{m}$ are subtle in comparison to the features of the mineral substrates, thus hindering direct identification of the PHC spectrally. However, the PHC coating of the grains increased the emissivity of the background features - a finding that was supported by SEBASS data processing using a matched filtering technique. The SEBASS data indicated that besides an increase in the emissivity of the underlying substrates, the presence of PHC also induces a change in the temperature of the contaminated targets. The combination of these two factors highlighted the contaminated sites indirectly. Since the mapping of clean, moist and PHC contaminated sites with TIR data depends on variations in the emissivity and temperature of the targets, the application can be extended to orbital sensors with lower spectral resolution (such as ASTER and ECOSTRESS), enabling the monitoring of larger areas.
\end{abstract}

\section{Introduction}

The oil industry has historically invested in new and cleaner methods for targeting petroleum plays in frontier basins. In parallel, the industry is also continuously interested to improve methods to map areas contaminated with crude oils and its derivatives (e.g. diesel, gasoline), and to assist in the monitoring and recovery of areas nearby active oil fields. Remote sensing fulfills all these demands. It is an efficient prospecting method and can also facilitate the risk assessment of areas affected by oil leaks, preventing contamination by hazardous components of petroleum hydrocarbons (PHC).

The infrared (IR) range is a versatile region for the detection of PHC through remote sensing techniques. Stretching vibrations and overtones of fundamental $\mathrm{C}-\mathrm{H}$ bands generate characteristic absorption features in the near, shortwave, midwave and thermal infrared (NIR-SWIRMWIR-TIR) (Silverstein and Bassler 1962), which can be used for PHC mapping. Applications using NIR-SWIR $(1-2.5 \mu \mathrm{m})$ sensors have been broadly explored. Several authors conducted studies investigating field and airborne spectrometers to detect contaminated soils directly through the identification of PHC doublets around 1.7 and $2.3 \mu \mathrm{m}$ (Correa Pabón and Souza Filho, 2016; Correa Pabón and Souza Filho, 2019; Scafutto et al. 2017; Scafutto and Souza Filho, 2016; Van der Meer et al. 2002); and indirectly through surface alterations induced by the presence of PHC underground (Asadzadeh and de Souza Filho 2017;

\footnotetext{
* Corresponding author.

E-mail addresses: rebecca.scafutto@gmail.com (R.D.M. Scafutto), c.lievens@utwente.nl (C. Lievens), c.a.hecker@utwente.nl (C. Hecker), f.d.vandermeer@ utwente.nl (F.D. van der Meer), beto@ige.unicamp.br (C.R. Souza Filho).
} 
(A) PHC SPECTRA - NIR/SWIR

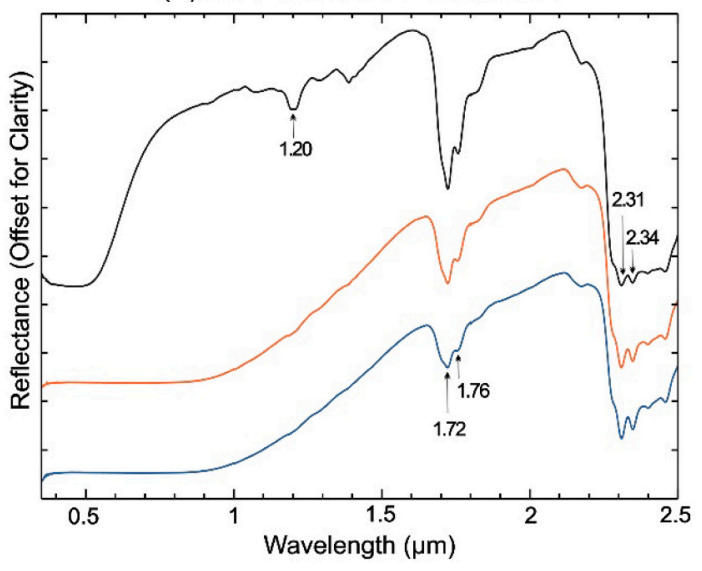

(B) PHC SPECTRA - MWIR/LWIR

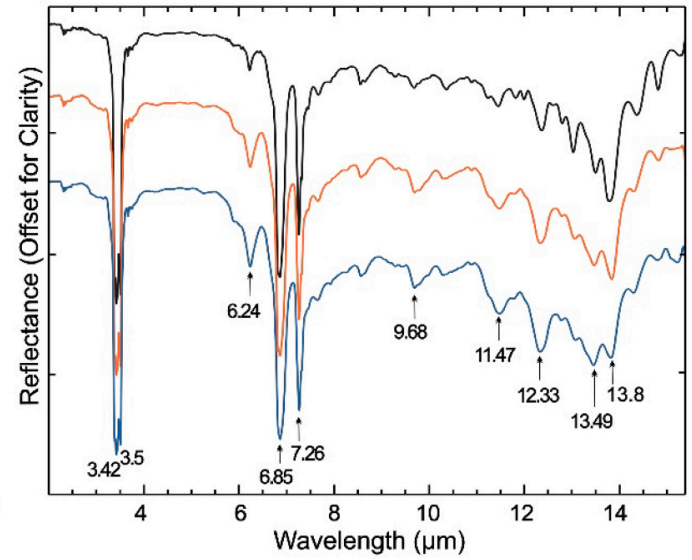

-BR_API 43.2 OBR_API 27.5 BR_API 19.7

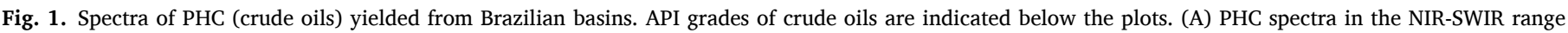

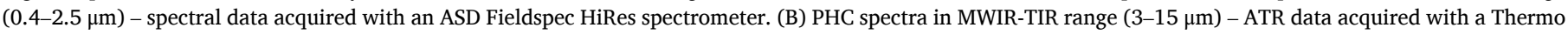
Fisher Nicolet 6700 spectrometer. Arrows point PHC features (adapted from Correa Pabón and Souza Filho, 2019; Scafutto and Souza Filho, 2016).

Sanches et al. 2013; Schumacher 1996). Simulations and real case scenarios with the WorldView-3 (WV-3) orbital sensor also indicate that these data are promising for large scale mapping (Asadzadeh et al. 2019; Asadzadeh and Souza Filho 2016). Despite the success, the main disadvantage of the use of this spectral range lies in the misclassification of dry vegetation as oiled materials (Peterson et al. 2015). Absorption features related to cellulose and lignin arise in wavelengths similar to PHC components $(1.7$ and $2.3 \mu \mathrm{m})$, when the vegetation is at an advanced stage of senescence (Kokaly et al. 2013), leading to falsepositive anomalies.

MWIR (3-6 $\mu \mathrm{m})$ and TIR $(7-15 \mu \mathrm{m})$ instruments have gathered more attention in recent years. Studies using cameras mounted in aircraft (airborne) or on tripods (fixed) describe mostly applications for the detection of gaseous PHC (Hulley et al. 2016; Scafutto and Souza Filho 2018; Tratt et al. 2014). Webster et al. (2016) have shown the application of a hand-held spectrometer to detect detection and to estimate concentrations of total petroleum hydrocarbons (TPH) in soil samples, using strong PHC features located at 3.4-3.5 $\mu \mathrm{m}$ (MWIR) (Fig. 1). Applications of TIR instruments for the detection of oiled samples are limited (van der Meijde et al. 2013), due to weak spectral features in this range when compared to NIR-SWIR-MWIR ranges (Correa Pabón and Souza Filho, 2019). However, previous experiments conducted in the laboratory (van der Meijde et al. 2013) and in the field (Pelta and BenDor 2019) indicate that close-range TIR hyperspectral measurements can detect contaminated soils through variations in the spectral features of minerals induced by the addition of PHC.

Here, the applicability of TIR data for the detection of soils contaminated with PHCs is investigated. Controlled experiments in laboratory and field conditions were conducted to (i) identify the PHC spectral features and changes induced by the contaminant in the spectra of mineral substrates in soil-PHC mixtures between 3 and $15 \mu \mathrm{m}$ (MWIRTIR); and (ii) to assess the possibility for direct or indirect detection of contaminated sites in a larger scale, using the SEBASS (SpatiallyEnhanced Broadband Array Spectrograph System) airborne hyperspectral TIR sensor (7.5-13.5 $\mu \mathrm{m})$. On top of evaluating the sensitivity and limitations of TIR airborne data to map PHC leakage or seepage in continental sites, the advantages and disadvantages concerning NIRSWIR data applied to the same tasks are also analyzed. Results yielded from SEBASS are contrasted against those obtained from the ProSpecTIR-VS airborne hyperspectral sensor (0.4-2.5 $\mu \mathrm{m}-$ e.g. Scafutto et al. 2017) over the same field experiment.

\section{PHC spectral features (NIR-SWIR-MWIR-TIR)}

PHCs have fingerprint spectral features in both NIR-SWIR and MWIR-TIR ranges, which largely fall within the terrestrial atmospheric windows (i.e. $0.4-2.5 \mu \mathrm{m}, 3-5 \mu \mathrm{m}$ and $7-14 \mu \mathrm{m}$ ) and potentially could be used for remote sensing PHC detection. In the NIR-SWIR interval, PHCs have two main double features located around 1.7 and $2.3 \mu \mathrm{m}$, related to stretch combinations and overtones of $\mathrm{CH}_{2}$ and $\mathrm{CH}_{3}$ (Cloutis 1989). PHC features appear in four major regions in the MWIR-TIR, which are mostly related to the $\mathrm{C}-\mathrm{H}$ stretching vibrations (symmetric and asymmetric) of methyl and methylene groups (3.3-3.7 $\mu \mathrm{m})$; the $\mathrm{C}-\mathrm{H}$ bend (symmetric and asymmetric) of the methyl group (5.8-7.9 $\mu \mathrm{m})$; the $\mathrm{C}-\mathrm{H}$ in-plane $(8-10 \mu \mathrm{m})$ and out-of-plane $(11-14 \mu \mathrm{m})$ bends of aromatic compounds (Lammoglia and Souza Filho 2011; Correa Pabón and Souza Filho, 2019; Stuart 2004). The doublet feature with peaks at 3.42/3.5 $\mu \mathrm{m}$ and the two features at 6.85 and $7.26 \mu \mathrm{m}$ constitute the strongest absorptions in this range (Fig. 1). Some weak features are observed at $6.24 \mu \mathrm{m}$ (single), $9.68 \mu \mathrm{m}$ (single), $11.47 \mu \mathrm{m}$ (single), 12.33 $\mu \mathrm{m}$ (single) and 13.49/13.8 $\mu \mathrm{m}$ (doublet) as well.

\section{Materials and methods}

\subsection{Laboratory experiments}

Controlled experiments were performed in the geoscience laboratory of the Faculty of Geo-Information Science and Earth Observation (ITC University of Twente). The experiment involved TIR measurements of water, plant components (lignin and cellulose), mineral substrates (quartz-rich sand, montmorillonite, dolomite), light ( ${ }^{\circ} \mathrm{API} 43.2^{1}$ ), intermediate ( ${ }^{\circ}$ API 27.5$)$ and heavy ( ${ }^{\circ}$ API 19.7) crude oils from Brazilian basins, and the mixture of these materials in different proportions, as described below.

\subsubsection{Attenuated Total reflectance - ATR}

Attenuated Total Reflectance (ATR) is a Fourier-transform infrared

\footnotetext{
${ }^{1}$ The American Petroleum Institute gravity $\left(\mathrm{API}^{\circ}\right)$ is the standard specific gravity (i.e. density) used to classify liquid petroleum products $\left(\mathrm{API}^{\circ}=(141.5 /\right.$ Specific Gravity) - 131.5). The API gravity classifies crude oils as light $\left(\mathrm{API}^{\circ}>\right.$ 31 ), intermediate $\left(31>\mathrm{API}^{\circ}>22\right)$, heavy $\left(\mathrm{API}^{\circ}<22\right)$, or extra heavy $\left(\mathrm{API}^{\circ}<\right.$ $10)$.
} 


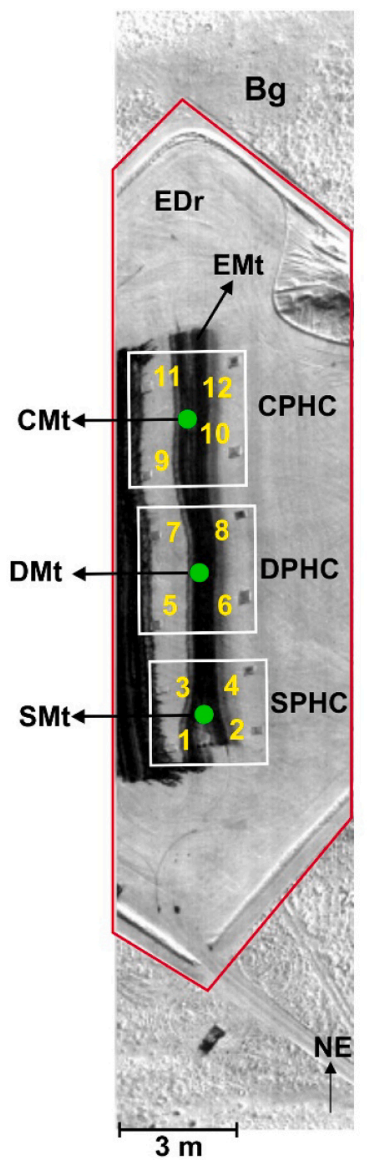

MINERAL SUBSTRATES - CONTAMINATED WITH PHC

SPHC

BOX 1: SAND + $\mathrm{OIL}^{\circ} \mathrm{API} 29$

BOX 2: SAND + OIL ${ }^{\circ} A P I 41$

BOX 3: SAND + OIL DIESEL

BOX 4: SAND + OIL GASOLINE

\section{DPHC}

BOX 5: DOLOMITE + OIL ${ }^{\circ} \mathrm{API} 29$

BOX 6: DOLOMITE + OIL ${ }^{\circ} \mathrm{API} 41$

BOX 7: DOLOMITE + OIL DIESEL

BOX 8: DOLOMITE + OIL GASOLINE

CPHC

BOX 9: CLAY + OIL ${ }^{\circ} A P I 29$

BOX 10: CLAY + OIL ${ }^{\circ} A P I 41$

BOX 11: CLAY + OIL DIESEL

BOX 12: CLAY + OIL GASOLINE

MINERAL SUBSTRATES - UNCONTAMINATED

SMt: LEFTOVERS OF SAND RICH SUBSTRATE

Dmt: LEFTOVERS OF DOLOMITE RICH SUBSTRATE

Cmt: LEFTOVERS OF CLAY RICH SUBSTRATE

\section{UNCONTAMINATED BACKGROUND}

EMt: MOIST SOIL INSIDE EXPERIMENTAL SITE

EDr: DRY SOIL INSIDE EXPERIMENTAL SITE

Bg: DRY SOIL OUTSIDE EXPERIMENTAL SITE
Fig. 2. Field experiment: SEBASS image (Band $10-8.2 \mu \mathrm{m}$ ) showing the arrangement of the twelve boxes with soil-PHC mixtures in the field. SPHC, DPHC, and CPHC correspond to boxes with mineral substrates rich in sand, dolomite and clay contaminated with varied PHCs. The content of each box is listed next to the figure. Green circles correspond to uncontaminated moist leftovers of sand (SMt), dolomite (DMt), and clay (CMt) rich mineral substrates, which were stockpiled around the center of a polygon comprising each set of 4 boxes. Other uncontaminated elements in the scene include moist (EMt) and dry (EDr) background soils inside the area of the experiment (delimited by the red line in the figure); and the dry background soil outside the area of the experiment (Bg). (For interpretation of the references to colour in this figure legend, the reader is referred to the web version of this article.) spectroscopy (FTIR - spectroscopy) technique in which the transmittance of a material is obtained with a crystal with a high refractive index. An IR beam is directed towards the edge of the ATR crystal at such an angle that the beam undergoes multiple reflections within the crystal (Luz 2006). Although the IR beam is totally internally reflected, an evanescence wave (i.e. electric field) extends a short distance beyond the crystal, interacting with a thin surface layer of the sample placed above, generating the ATR spectrum (Spragg 2017). As the evanescent wave penetrates only a few microns into the sample, ATR only measures the very surface properties of the material (Spragg 2017). Here, ATR was deployed to identify absorption features of the functional groups (i.e. fundamental vibrations) related to the composition of the samples under study.

ATR measurements were made with a Bruker Vertex 70 FTIR Spectrometer (Hecker et al. 2011), using a Pt-ATR-Diamond accessory (see Fig. S1 in the supplementary material). Samples were measured in absorbance (average of 3 measurements) within the spectral range of 2.5-16 $\mu \mathrm{m}\left(4000-625 \mathrm{~cm}^{-1}\right)$ with a spectral resolution of $4 \mathrm{~cm}^{-1}$. Each record is consisted of an average of 16 scans and is baseline corrected.

3.1.1.1. Sample preparation. Firstly, powder mineral substrates and plant components were dried for $24 \mathrm{~h}$ in an oven at $105^{\circ} \mathrm{C}$. Due to large grain sizes, the sandy samples were ground in a ball mill, using 2 jars of zirconium dioxide $\left(\mathrm{ZrO}_{2}\right)$ for $5 \mathrm{~min}$ at $500 \mathrm{rpm}$. Once dried, cellulose and lignin were mixed at a ratio of 2:1 (the rate of cellulose:lignin will vary depending on the species, however, the content of cellulose will be usually higher than the lignin - e.g. McKendry 2002). The mixture was homogenized in the ball mill, using 2 jars of zirconium dioxide $\left(\mathrm{ZrO}_{2}\right)$, for $10 \mathrm{~min}$ at $200 \mathrm{rpm}$. The mixture of cellulose and lignin is referred here onwards as CL. ATR measurements were taken from dried mineral substrates, CL mixture, crude oils, and water.

\subsubsection{Directional-hemispherical reflectance - DHR}

DHR yields from the integration of the partial reflectance of a surface element across the angle of a hemisphere (Nicodemus 1965). The surface of the sample is directly irradiated with an IR beam, and the hemispherical reflectance of the surface (both diffuse and specular components) is measured with an integrating sphere. DHR introduces the scattering and three-dimensional effects from the surface not present in the ATR measurements, which enables emissivity estimation from DHR data, using the Kirchhoff's law (i.e. $\varepsilon=1-$ DHR); and allows a quantitative comparison of the measurements with airborne emissivity data (Luz and Crowley 2007; Nicodemus 1965; Salisbury and D'Aria 1994).

DHR measurements were acquired in the $1.4-16 \mu \mathrm{m}\left(4 \mathrm{~cm}^{-1}\right.$ resolution) spectral range at ITC, with an integrating sphere coupled to a Bruker Vertex 70 FTIR Spectrometer (see Fig. S1 in the supplementary material). The design of the spectrometer was modified and adapted so that the DHR spectra were comparable to emission spectra (TIR) from remote sensors (Hecker et al. 2011). The sphere has a diameter of 150 $\mathrm{mm}$ and is gold-coated internally ( $3 \mu \mathrm{m}$ of thickness) (Hecker et al. 2011). The MCT (Mercury Cadmium Telluride) TIR detector on the top of the sphere is cooled with liquid nitrogen $60 \mathrm{~min}$ prior to the first measurements, and $30 \mathrm{~min}$ before resuming measurements, if refilling is needed in mid-campaign. The system is continuously purged with $\mathrm{N}_{2}$ $(200 \mathrm{~L} / \mathrm{h})$ during a series of measurements to reduce water vapor and $\mathrm{CO}_{2}$, as well as to ensure system stability. During the measurements, a $\mathrm{KBr}$ window is placed between the integrating sphere and the FTIR instrument to prevent possible contamination of the instrument optics and the interferometer by PHC volatiles. 

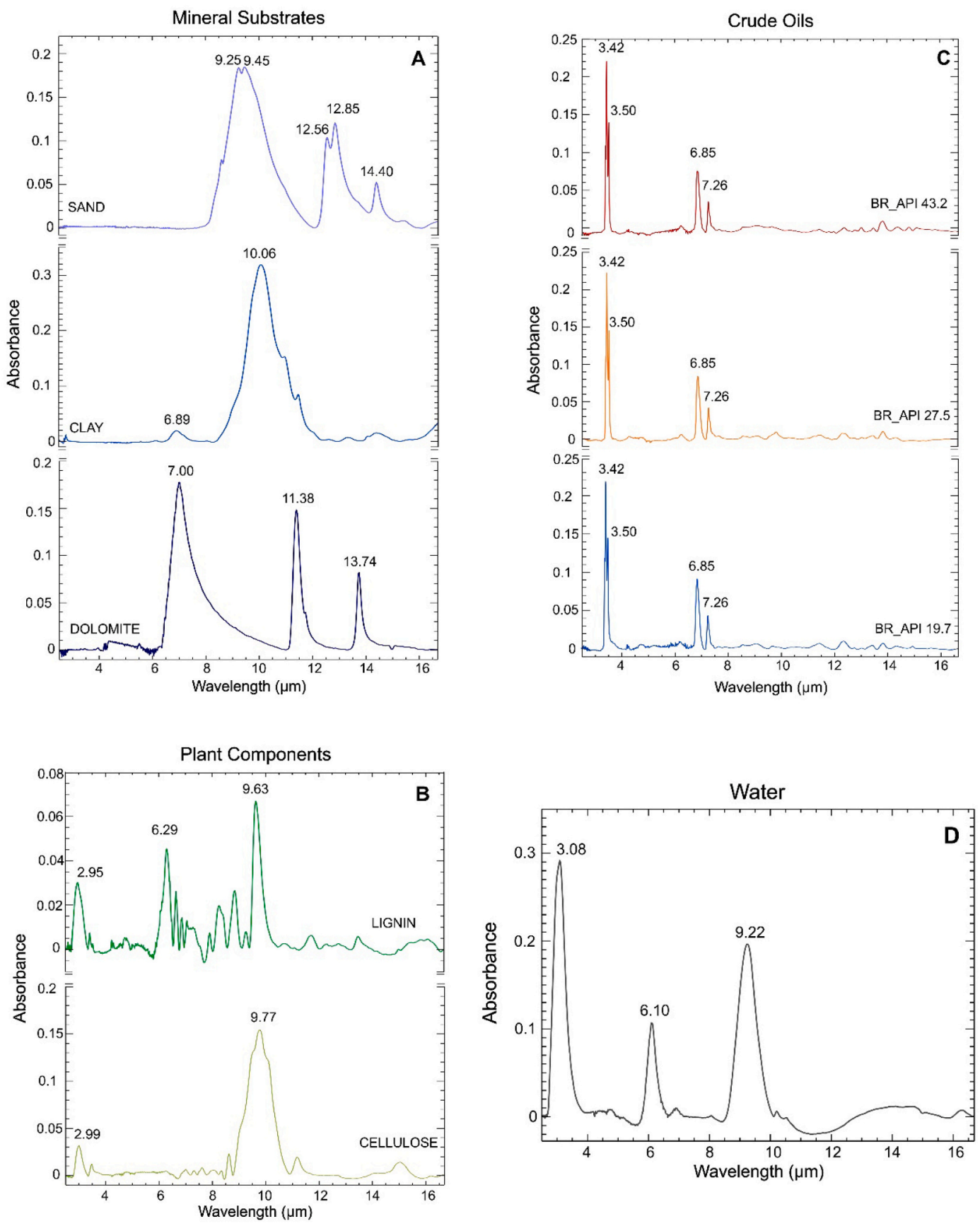

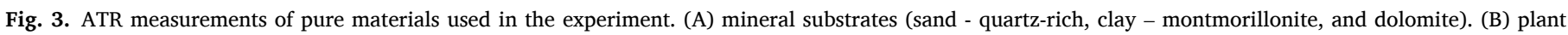

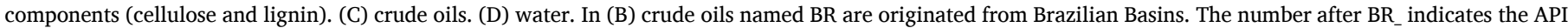
grade of each sample.

The system was calibrated with a gold standard before each sample. Background radiation (i.e. dark current) measurements were taken once a day, which was used to correct elevated reflectance values. Each measurement consists of 512 scans. The resulting DHR spectra consist of the mean spectrum of 8 measurements per sample. Collected data were processed using the HypPy Tools program, which converts absolute directional-hemispherical reflectance to emissivity through Kirchhoff's Law. Further details of the spectrometer configuration and calculation of emissivity spectra are given in Hecker et al. (2011).

3.1.2.1. Sample preparation. The same mineral substrates (dried for 24 h) prepared for ATR measurements were used in this experiment. To simulate the conditions of the field experiment (see below), measurements were performed on dry mineral substrates, dry substrate moistened with $5 \% \mathrm{~W}$ of water, dry substrate contaminated with $5 \% \mathrm{~W}$ of intermediate crude oil ( ${ }^{\circ} \mathrm{API} 27.5$ ), and dry substrate $+5 \% \mathrm{~W}$ of water $+5 \% \mathrm{~W}$ of crude oil ( ${ }^{\circ} \mathrm{API} 27.5$ ), totaling twelve samples. All mixtures were prepared and homogenized by hand and then measured spectrally.

\subsection{Field experiment}

A controlled field experiment planned to simulate soil contaminations by PHC leakage was performed in 2010, at the Rocky Mountain Oilfield Testing Center (RMOTC), located in Casper, WY (USA) (see Fig. 

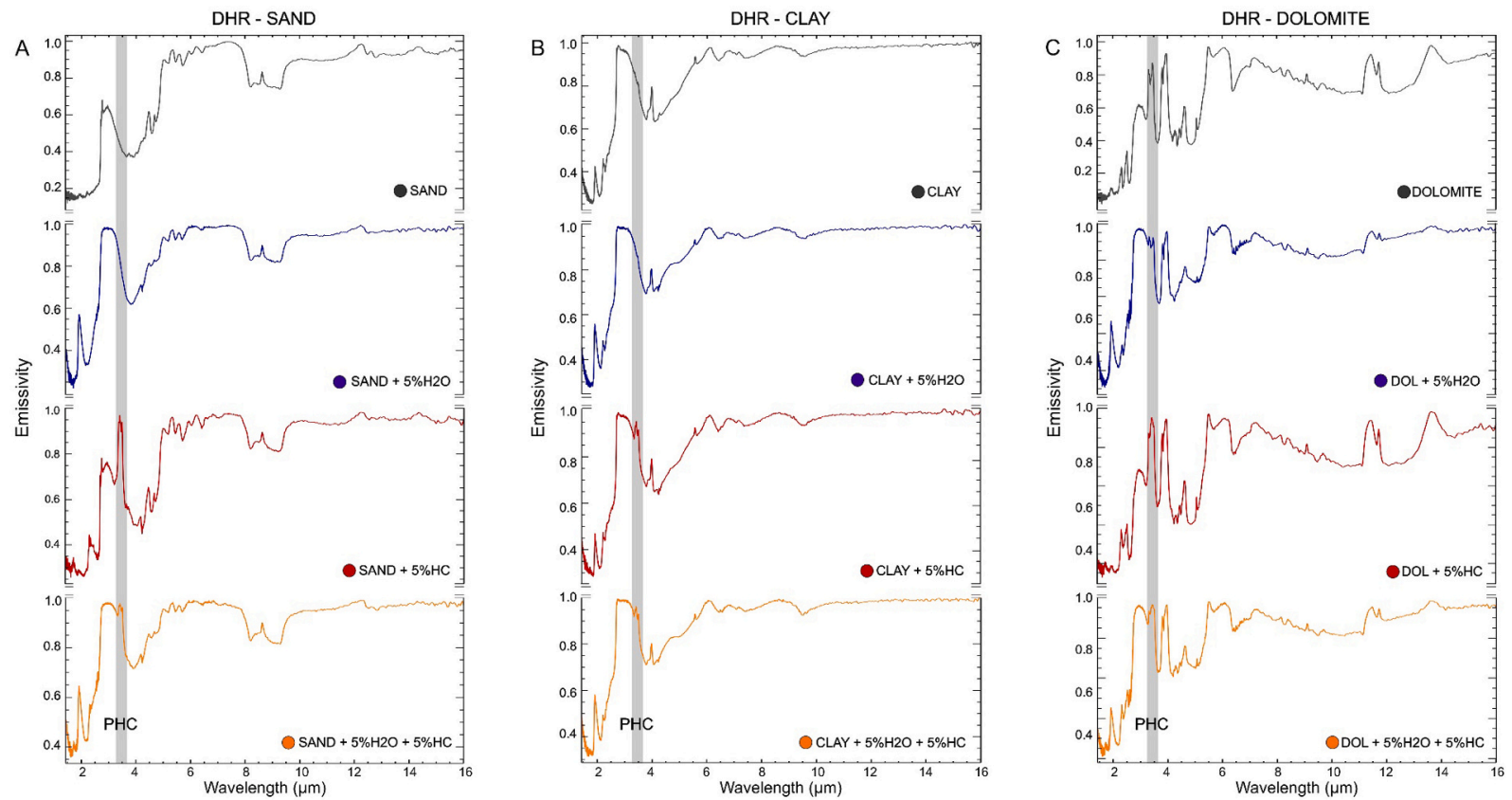

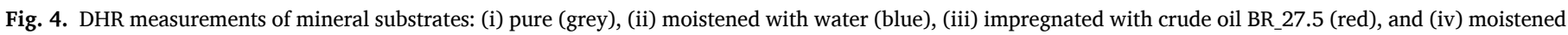

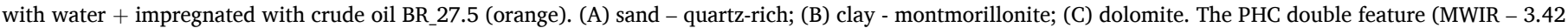

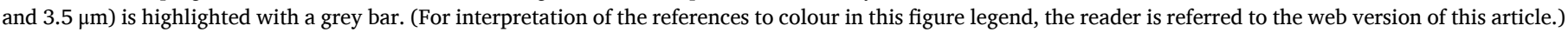

S2 in the supplementary material). Three mineral substrates with varied grain size and composition and four types of PHC were used during the simulations. The PHC collection was comprised of two crude oils ( ${ }^{\circ} \mathrm{API}$ 29 and 41), diesel, and gasoline. Soils rich in sand (quartz), clay (montmorillonite), and carbonate (dolomite) made up the background mineral substrates (Fig. 2).

In the field, $0.40 \mathrm{~m}^{3}$ of each mineral substrate were mixed with three loads of $18 \mathrm{~L}$ of every liquid PHC. At the end of the experiment, every substrate was contaminated with $54 \mathrm{~L}$ of the respective PHC. The contaminants were added $1 \mathrm{~h}, 30 \mathrm{~min}$ and $15 \mathrm{~min}$ before the aerial survey. The mixtures soil-PHC (12 in total) were prepared in the field, in wooden boxes $(2.44 \mathrm{~m} \times 2.44 \mathrm{~m} \times 0.15 \mathrm{~m})$ properly prepared to avoid background contamination. After filling the boxes, leftovers of each mineral substrate (not impregnated with PHC) were stockpiled closely to their respective set of boxes (Fig. 2). Additionally, surrounding areas (i. e. background soil + leftovers of mineral substrates around the boxes) were moistened with water to resemble wet sediments and soils (Fig. 2).

\subsubsection{Field data}

Samples from the background soil (dry and moistened) and contaminated mineral substrates (inside each box) were collected and measured in the USGS laboratory (Reston, VA/USA). DHR measurements from field samples were acquired using an integrating sphere (127 mm diameter) attached to the Nicolet Nexus 670 spectrometer (Luz and Crowley 2007).

Imaging data were acquired with the SEBASS (TIR) and ProSpecTIRVS (NIR-SWIR) airborne hyperspectral sensors on August 20, 2010. The data analyzed from the SEBASS sensor were acquired only at the end of the experiment (i.e. when the boxes were contaminated with $54 \mathrm{~L}$ of PHC). The SEBASS thermal imaging spectrometer collects 128 contiguous bands between 7.6 and $13.5 \mu \mathrm{m}$, at $0.05 \mu \mathrm{m}$ spectral resolution. The images were acquired using an IFOV of $1.1 \mathrm{mrad}$, at a flight altitude of $457 \mathrm{~m}$, which gives a spatial resolution of $0.5 \mathrm{~m}$. Therefore, contaminated boxes are represented by $\sim 25$ pixels in the image. Scafutto et al. (2017) describe the field experiment in detail. The ambient air temperature measured by the RMOTC station during the flight was at 30.5 ${ }^{\circ} \mathrm{C}$.

\subsubsection{Image processing}

The SEBASS imagery was processed according to the following protocol: (i) atmospheric compensation; (ii) emissivity and temperature retrieval; (iii) wavelet transformation; (iv) classification using a Mixture Tuned Matched Filter (MTMF) algorithm. The atmospheric compensation was performed using the in-scene atmospheric compensation (ISAC) algorithm of Young et al. (1998), Young et al. (2002); as implemented in the ENVI software (Distasio and Resmini 2010). Only the calibrated ataperture radiance data is necessary as an input to estimate the ground leaving radiance (GLR) for each pixel. Therefore, information such as ozone concentration, water vapor concentration and atmospheric temperature is not necessary to apply for the method to be implemented.

Emissivity and temperature data were derived with the Emissivity Normalization method (NOR - Li et al. 1999), which uses the compensated data as input (Distasio and Resmini 2010). A wavelet transform (Scafutto and Souza Filho 2018) was applied to suppress noise and enhance the spectral features. Next, the MTFM classification algorithm (Boardman and Kruse 2011) was employed to map oiled targets in the scene by making use of endmembers manually extracted from the imagery. Average spectra from each class mapped by MTMF was estimated using ROIs (regions of interest) defined over contaminated boxes and uncontaminated targets (Fig. 5).

\section{Results}

\subsection{Laboratory experiments}

\subsection{1. $A T R$}

The absorbance spectra of pure samples and mixtures are presented in Fig. 3. Three main features were recognized in PHC (crude oils) spectra (Fig. 3C): a doublet with peaks at $3.42 \mu \mathrm{m}$ and $3.50 \mu \mathrm{m}(\mathrm{C}-\mathrm{H}$ stretching vibrations) and two single features at $6.85 \mu \mathrm{m}$ and $7.26 \mu \mathrm{m}$ (C-H bend) (Lammoglia and Souza Filho 2011).

In the sand spectra (Fig. 3A), spectral features correspond to asymmetric $(9.25 / 9.45 \mu \mathrm{m})$ and symmetric $(12.56 / 12.85 \mu \mathrm{m}$ and $14.40 \mu \mathrm{m})$ Si-O-Si stretching (Suart 2004). Features at $6.89 \mu \mathrm{m}$ and $10.06 \mu \mathrm{m}$ in the spectra of clay (Fig. 3A) are related to bending vibration of water 

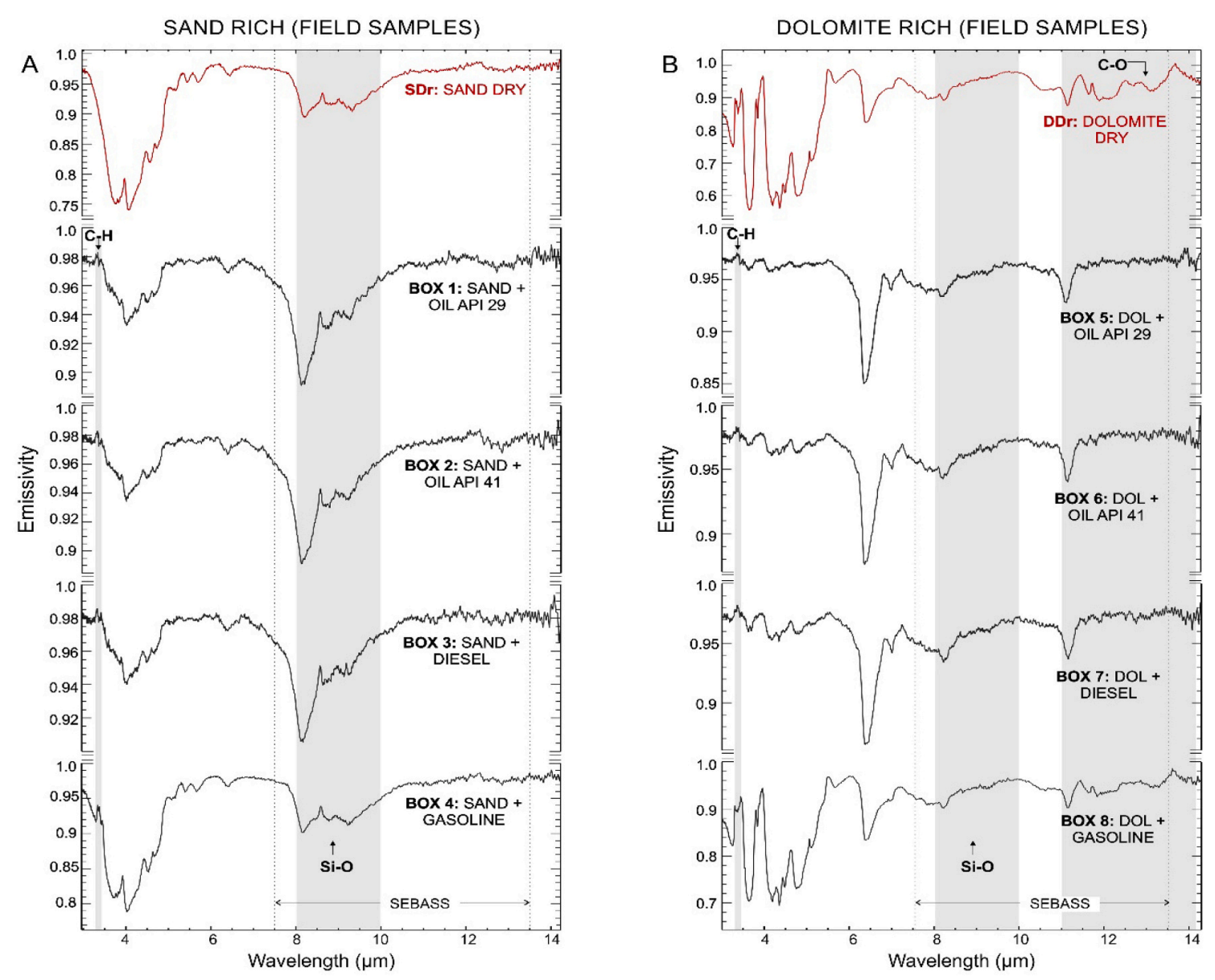

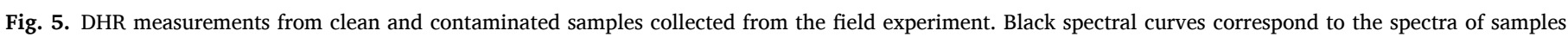

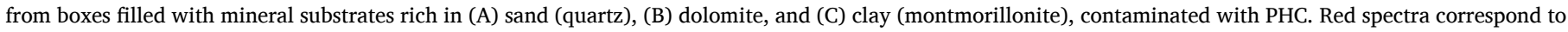

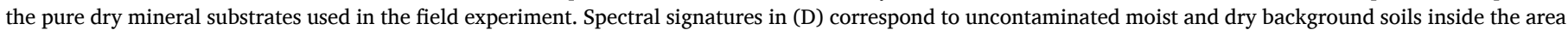

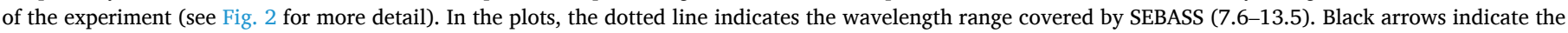

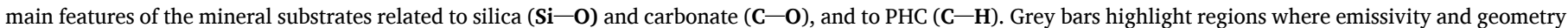

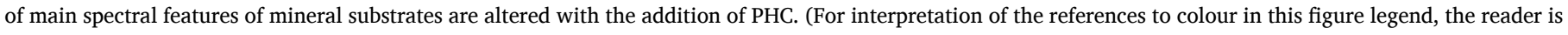
referred to the web version of this article.) 

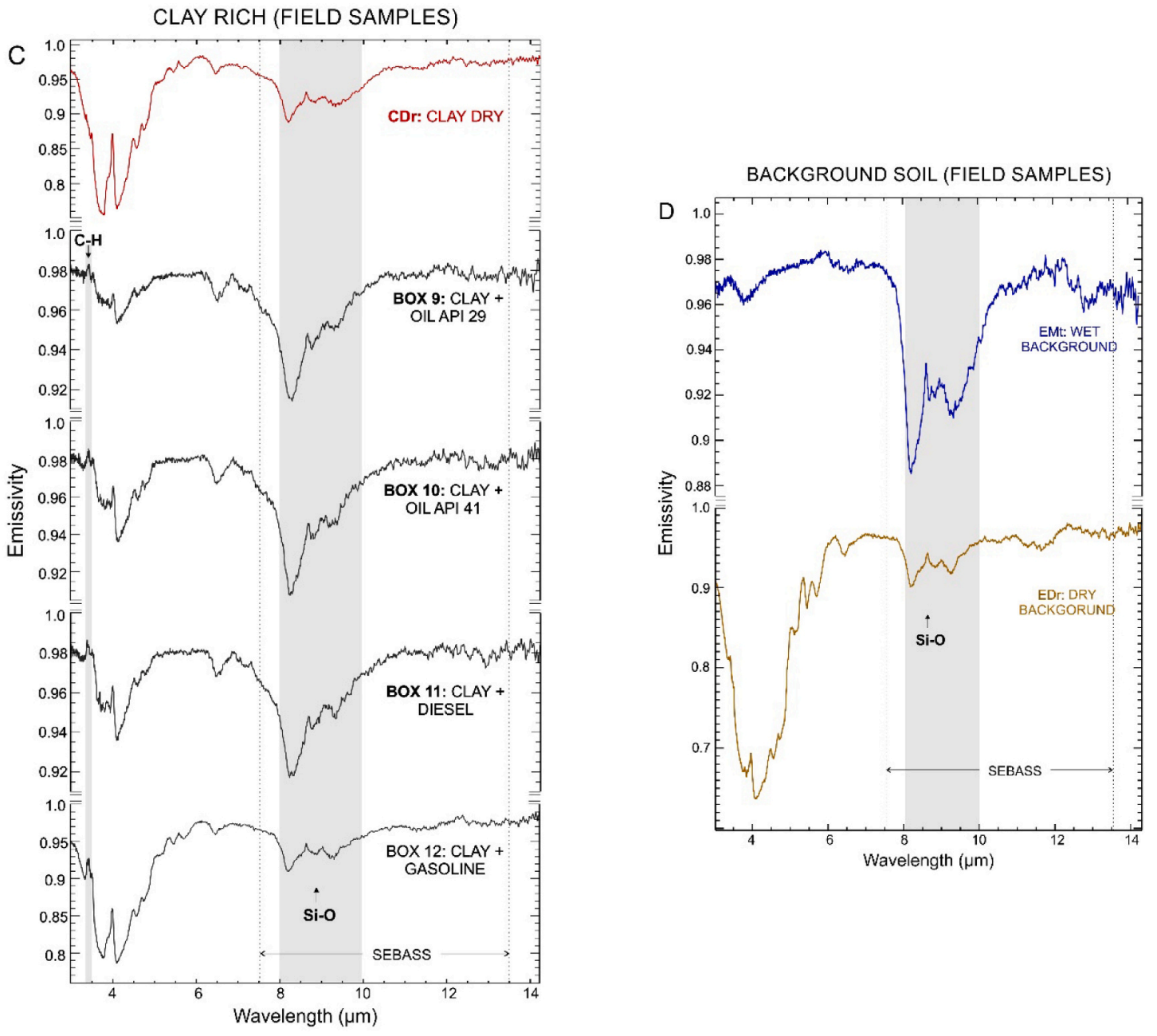

Fig. 5. (continued).

structural molecules and (Al, Si)-O stretching vibrations (Yitagesu et al. 2011), respectively. Spectral features of dolomite (Fig. 3A) correspond to $\mathrm{CO}_{3}$ fundamental vibrations ( $7 \mu \mathrm{m}=$ out-of-plane bend, $11.38 \mu \mathrm{m}=$ asymmetric stretch and $13.74 \mu \mathrm{m}=$ in-plane bend) (Green and Schodlok 2016).

Lignin and cellulose have several spectral features in the TIR range (Fig. 3B). The most prominent features of lignin are located at $6.29 \mu \mathrm{m}$ ( $\mathrm{COOH}$ aromatic skeletal vibrations) and $9.63 \mu \mathrm{m}(\mathrm{C}-\mathrm{H}$ in-plane deformation) (Elvidge 1988). The prominent feature at $9.77 \mu \mathrm{m}$ in the spectrum of cellulose is related to skeletal vibrations of $\mathrm{C}-\mathrm{O}$ stretching (Elvidge 1988). The feature around $3 \mu \mathrm{m}$ corresponds to $\mathrm{OH}$ stretching in both lignin and cellulose spectra (Elvidge 1988). Spectral features of water (Fig. 3D) correspond to stretching $(3.08 \mu \mathrm{m})$ and bending $(6.10$ $\mu \mathrm{m}$ and $9.22 \mu \mathrm{m}$ ) of hydroxyl (Suart 2004).

The ATR measurements of uncontaminated materials show that the PHC doublet $(\sim 3.5 \mu \mathrm{m})$ is isolated in the 3-6 $\mu \mathrm{m}$ range in comparison to mineral substrate signatures. Even though lignin and cellulose have peaks around $3 \mu \mathrm{m}$ and $6.3 \mu \mathrm{m}$, their absorbance is weak and unlikely to interfere with PHC detection. Between 6 and $14 \mu \mathrm{m}$, the mineral substrates have strong and wide features that would probably overlap the PHC feature in a mixture of soil and PHC. Water has features located at wavelengths close to PHC peaks, which could also influence PHC detection due to the high absorptance and width of water features.

\subsection{2. $D H R$}

The emissivity spectra of pure samples and mixtures are presented in
Fig. 4. Compared to the oil spectra in the ATR measurements, only the doublet feature of the PHC at $3.5 \mu \mathrm{m}$ can be identified in the spectra of soil-PHC mixtures. The PHC features at $6.85 \mu \mathrm{m}$ and $7.26 \mu \mathrm{m}$ were not detected in the DHR results.

Spectral features of mineral substrates are predominant in the signatures. For mixtures with dolomite (Fig. 4B), the substrate displays doublet features at similar wavelengths of the PHC doublet $(3.5 \mu \mathrm{m})$, which can lead to misclassification in areas with predominant carbonate composition. In general, water plays a significant role in all mixtures. The features of the mineral substrates and PHC are weakened in the signature of moist soils. The same is not observed in the water-free mixtures of substrate-PHC.

The geometry of the PHC feature in $3.5 \mu \mathrm{m}$ also varies depending on the mineral substrate. In the mixture between sand and PHC (Fig. 4A), the doublet feature of the contaminant is clearly visible and maintains a high emissivity. Due to the overlap of PHC with dolomite features at 3.5 $\mu \mathrm{m}$, the shape of the PHC features is modified, making it difficult to identify PHC where they form mixtures with dolomite (Fig. 4B). In the clay-PHC mixture (Fig. 4C), the emissivity of the contaminant at $\sim 3.5$ $\mu \mathrm{m}$ is smaller compared to the same feature in the other mixtures. This is possibly due to water in the structure of this mineral substrate (identified through the water feature at $\sim 1.9 \mu \mathrm{m}$, in the signature of uncontaminated clays).

Although PHC and water cannot be detected directly through their spectral features in the TIR $(7-15 \mu \mathrm{m})$, the layer of the liquid coating the grains causes variations in the emissivity values and geometry of the 


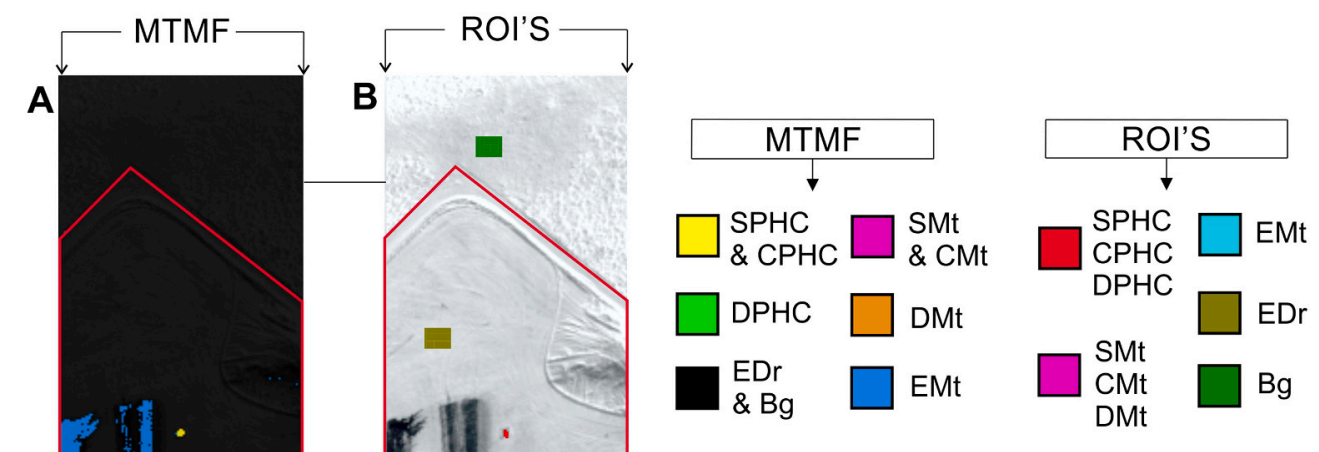

\section{LEGEND}

MINERAL SUBSTRATES -

CONTAMINATED WITH PHC

SPHC: SAND RICH SUBSTRATE (BOXES 1-4)

DPHC: DOLOMITE RICH SUBSTRATE (BOXES 5-8)

CPHC: CLAY RICH SUBSTRATE (BOXES 9-12)

\section{MINERAL SUBSTRATES - UNCONTAMINATED}

SMT: LEFTOVERS OF SAND RICH SUBSTRATE Dmt: LEFTOVERS OF DOLOMITE RICH SUBSTRATE Cmt: LEFTOVERS OF CLAY RICH SUBSTRATE

\section{UNCONTAMINATED BACKGROUND}

EMt: MOIST SOIL INSIDE EXPERIMENTAL SITE EDr: DRY SOIL INSIDE EXPERIMENTAL SITE Bg: DRY SOIL OUTSIDE EXPERIMENTAL SITE

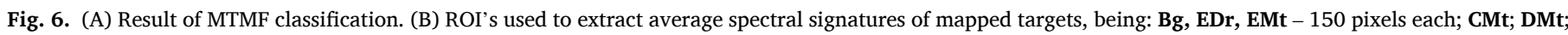

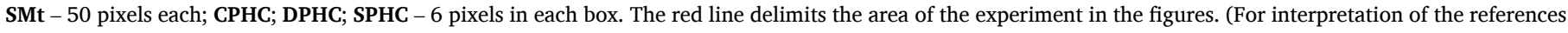
to colour in this figure legend, the reader is referred to the web version of this article.)

spectra of mineral substrates. The addition of both water and PHC in the mixture leads to an increase in the emissivity of the spectra of mineral substrates. This variation can be mainly noted in the mixtures with the sand-rich substrate (Fig. 4A), where the emissivity features related to silica between 8 and $10 \mu \mathrm{m}$ (Si-O-Si asymmetric stretch - Hunt 1980; Stuart 2004) in the signature of moist and PHC contaminated samples are higher than the same features in the signature of the pure dry sample. This difference in emissivity related to the addition of PHC was also reported by Pelta and Ben-Dor (2019). van der Meijde et al. (2013) described a reduction in the depth of soil features with the addition of PHC. However, as can be seen in Fig. 4, variations in the geometry of the features of mineral substrates in the DHR spectra of pure and contaminated samples are subtle in the samples analyzed in this study.

\subsubsection{Field experiment}

DHR measurements from field samples are presented in Fig. 5. The spectral collection includes dry sand-rich (SDr), clay-rich (CDr), and dolomite-rich (DDr) mineral substrates; PHC contaminated mineral substrates collected from boxes 1-12; and uncontaminated moist (EMt) and dry (DMt) samples from the background soil, within the area of the experiment. In this spectral collection, the PHC doublet $(\sim 3.5 \mu \mathrm{m})$ was identified in the signature of contaminated samples (Fig. 5), although this feature is more prominent in the spectra of mineral substrates contaminated with gasoline. Subtle PHC single features at $6.8 \mu \mathrm{m}$ and $7.3 \mu \mathrm{m}$ were identified in the spectra of contaminated dolomite-rich mineral substrates.
In the range covered by SEBASS (7.6-13.5 $\mu \mathrm{m})$, PHC features were not detected. Nevertheless, variation in the emissivity signature of mineral substrates between 8 and $10 \mu \mathrm{m}$, noted in the DHR spectra from the laboratory experiments (Fig. 4), was also observed in the spectra of the samples collected from the field experiment (Fig. 5). Features located at $8.8 \mu \mathrm{m}$ and $9.2 \mu \mathrm{m}$, in particular, have higher emissivity values in the spectra of PHC contaminated samples $(\sim 0.94)$ than in the spectra of pure $(\sim 0.91)$ and moist $(\sim 0.91)$ substrates. Since these silicaassociated features (Hunt 1980; Suart 2004) are common in all spectral collection from the field experiment samples (Fig. 5), it indicates that all mineral substrates used in the field experiment have a percentage of quartz mixed in the composition. Furthermore, in the spectra of dolomite-rich substrates, such a variation in emissivity is also observed between 11 and $14 \mu \mathrm{m}$ where the diagnostic vibrational absorption bands of $\mathrm{CO}_{3}$ occur (Clark 1999; Green and Schodlok 2016).

The classification results of the SEBASS data are presented in Fig. 6. Six classes are mapped: (1) boxes filled with PHC-contaminated mineral substrates rich in sand (SPHC, box 1-4) and clay (CPHC, box 9-12); (2) boxes filled with PHC-contaminated mineral substrates rich in dolomite (DPHC, box 5-8); (3) leftover residues of moist uncontaminated mineral substrates (between the two rows of contaminated boxes) rich in sand (SMt) and clay (CMt); (4) leftover residues of moist uncontaminated mineral substrates (between the two rows of contaminated boxes) rich in dolomite (DMt); (5) moist areas within the area of the experiment (EMt); (6) dry background soil (within - EDr and outside - Bg the area of the experiment). 

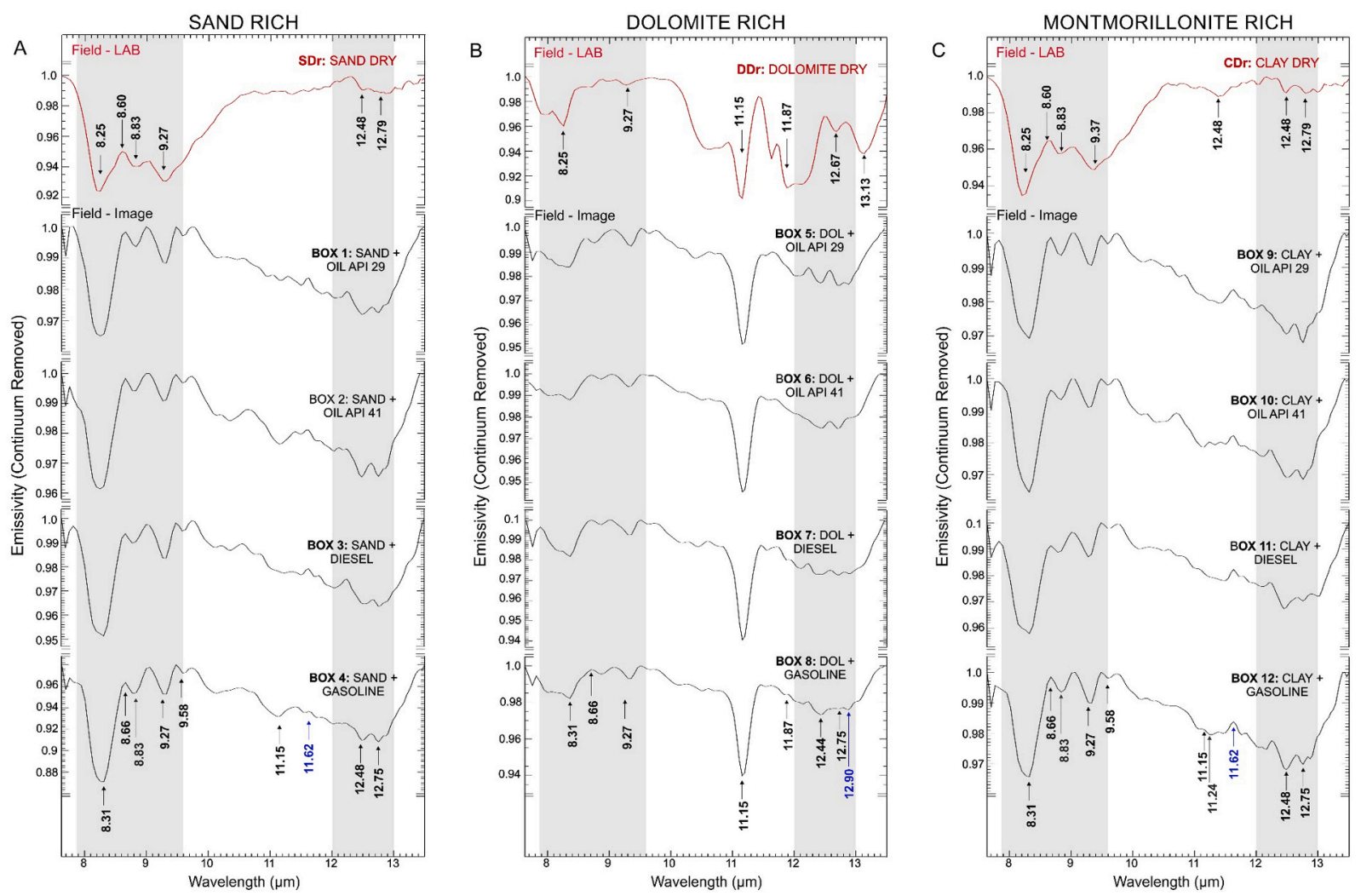

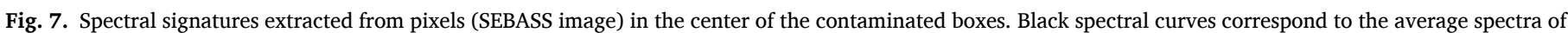

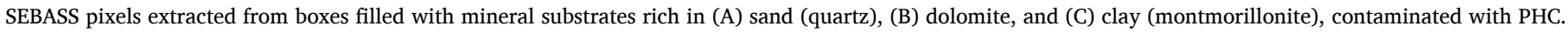

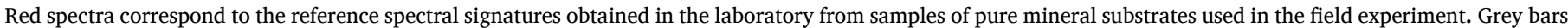

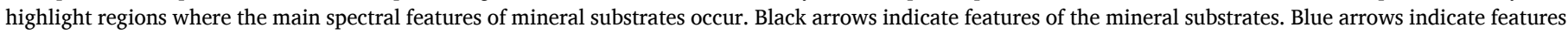

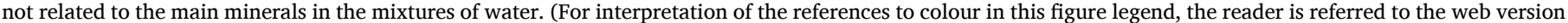
of this article.)

Average spectra from six pixels extracted from the center of each contaminated box, in comparison to reference spectra of the same contaminated substrates measured in the laboratory, are displayed in Fig. 7. Average spectral signatures extracted from 150 pixels of uncontaminated moist (EMt) and dry (EDr and $\mathbf{B g}$ ) background soils are presented in comparison to the average spectra of PHC contaminated (Fig. 8a) and moist (uncontaminated leftovers - 50 pixels) mineral substrates (Fig. 8b). ROIs and specification of each class are shown in Fig. 6b.

The classification of SEBASS imagery (Fig. 6) shows a clear separation between contaminated boxes, moist and dry areas. Boxes filled with mineral substrate rich in dolomite can be differentiated from the boxes with mineral substrates rich in clay and sand, due to the strong carbonate feature at $11.15 \mu \mathrm{m}$ (Fig. 7b). Since the clay-rich and sand-rich mineral substrates have both clay and sand in different proportions, the boxes filled with these mineral substrates were mapped as the same class, due to similar composition and spectral signature (Fig. $7 \mathrm{a}$ and c). Some features that were not related to substrates between 11 and $13 \mu \mathrm{m}$ (identified by blue arrows in Fig. 7) may be related to aromatic compounds. Features located at $11.24 \mu \mathrm{m}, 12.90 \mu \mathrm{m}$, and $13.02 \mu \mathrm{m}$, may correspond to features of PHC located at $11.30 \mu \mathrm{m}, 12.87 \mu \mathrm{m}$, and 13.08 $\mu \mathrm{m}$, respectively, as identified by Correa Pabón and Souza Filho, 2019 and Silverstein and Bassler (1962).

Although contaminated boxes were classified separately from dry and moist background soils (Fig. 6a), spectral signatures of contaminated boxes are similar to the dry background (Fig. 8a) in the range covered by the airborne sensor. Most of the absorption features can be correlated to the ones identified in the spectra from pure substrates used in the experiment (measured in the lab - Fig. 5). Variations in the emissivity of features related to silica $(8.7 \mu \mathrm{m}$ and $9.2 \mu \mathrm{m})$ in the spectra from contaminated and uncontaminated classes were also identified in the spectral collection extracted from the SEBASS image (Fig. 8).

Moist substrates have a characteristic feature between 10 and $11 \mu \mathrm{m}$, which has low emissivity values at 10 and $11 \mu \mathrm{m}$, with an emissivity peak at $10.56 \mu \mathrm{m}$. This feature is prominent only in moist substrates, differentiating moist areas (i.e. background soil and residue of mineral substrates) from dry areas (Fig. 8b), and from PHC contaminated substrates (Fig. 8a). Even though the feature at $10.56 \mu \mathrm{m}$ can be identified in some of the PHC contaminated substrates, the increased emissivity value, in comparison with the shoulders at $10 \mu \mathrm{m}$ and $11 \mu \mathrm{m}$, was only noticed in the signatures extracted from moist areas.

Fig. 9 shows the variation of temperature in the scene. Fig. 10 displays plots of temperature vs emissivity. Emissivity and temperature data were extracted from Band $29(9.2 \mu \mathrm{m})$ due to significant variations of emissivity values between uncontaminated moist soil (EMt, SMt, DMt, CMt), uncontaminated dry soil (EDr, Bg), and PHC-soil mixtures (SPHC, CPHC, DPHC) in this band.

Fig. 9 shows that dry soils, moist soils and PHC contaminated boxes have distinct temperatures. Dry and moist areas are respectively characterized by high $\left(\sim 40^{\circ} \mathrm{C}\right)$ and low $\left(\sim 25^{\circ} \mathrm{C}\right)$ temperatures, while PHC contaminated substrates have an average temperature in between these classes $\left(\sim 35{ }^{\circ} \mathrm{C}\right)$.

The combination of temperature and emissivity data reveal that substrates contaminated with PHC are bounded between 30 and $38{ }^{\circ} \mathrm{C}$ and $93-95 \%$ emissivity (Fig. 10A). Moreover, the same mineral substrates contaminated with PHC and moistened with water can be 

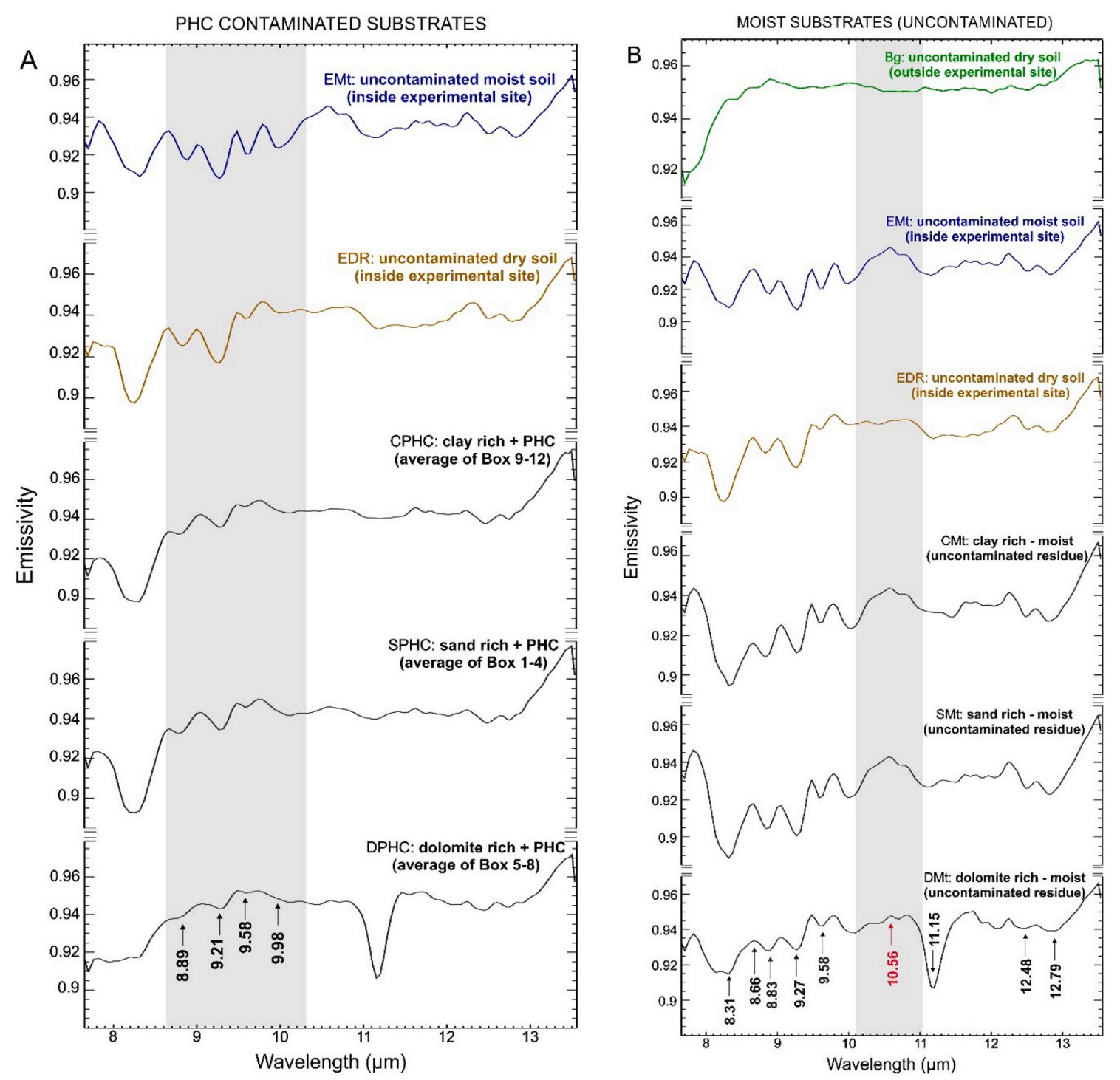

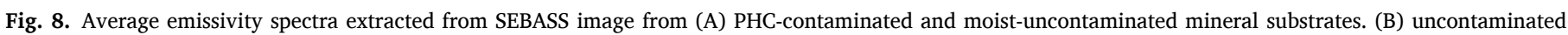

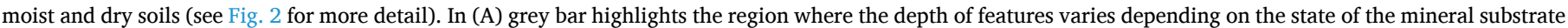

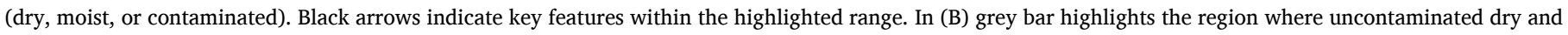

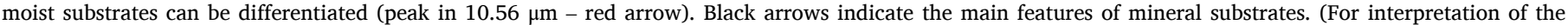
references to colour in this figure legend, the reader is referred to the web version of this article.)

separated using the same criteria (Fig. 10B), confirming that the variation in emissivity and temperature is more related to the moistening agent (water or PHC) rather than the composition or granulometry of the mineral substrates. This relation can also be observed when analyzing the contaminated boxes alone (Fig. 10C and D). Despite emissivity values being similar, the variation in the temperature of contaminated samples due to substrate composition is secondary in the separation of the samples compared to the PHC density of the contaminant. Substrates impregnated with heavy PHC show lower temperatures $\left(29-32{ }^{\circ} \mathrm{C}\right)$ compared to the lighter ones $\left(\sim 33-38{ }^{\circ} \mathrm{C}\right)$. In both cases, the dolomite rich substrate has the lowest temperatures $\left(\sim 29.5^{\circ} \mathrm{C}\right.$ and $\left.\sim 33^{\circ} \mathrm{C}\right)$. As regards the sand-rich and clay-rich substrates, the temperature is similar for boxes contaminated with crude oils (heavy $\sim 30-32{ }^{\circ} \mathrm{C}$, light $\sim 37.5$ ${ }^{\circ} \mathrm{C}$ ) and diesel $\left(\sim 36-37^{\circ} \mathrm{C}\right)$. For boxes impregnated with gasoline, there is a difference in the temperature from sand-rich $\left(\sim 37-38^{\circ} \mathrm{C}\right)$ and clayrich $\left(\sim 35^{\circ} \mathrm{C}\right)$ substrates.

\section{Discussion}

\subsection{Laboratory and field experiments}

Lammoglia and Souza Filho (2011) reported that PHC spectral features associated with $\mathrm{C}-\mathrm{H}$ stretching $(3.4$ and $3.5 \mu \mathrm{m})$ and bending $(6.8$ and $7.2 \mu \mathrm{m}$ ) are less significant in DHR spectra than those observed in ATR spectra of crude oils. Similar results are observed in the ATR (Fig. 3) and DHR (Fig. 4) measurements of soil-PHC mixtures. Subtle PHC features at longer wavelengths related to $\mathrm{C}-\mathrm{H}$ bend of aromatic compounds (Suart 2004) were not identified in both ATR and DHR measurements. In the TIR range (7-15 $\mu \mathrm{m})$, PHC has an overall flatter spectral response (Lammoglia and Souza Filho 2011), which, summed with the predominance of the spectral features of mineral substrates in soil-PHC mixtures (Fig. 4), hinders the identification of PHC features in this range.

Once laboratory results point that the direct detection of PHC using TIR data is unlikely, the indirect detection of the PHC contamination is 


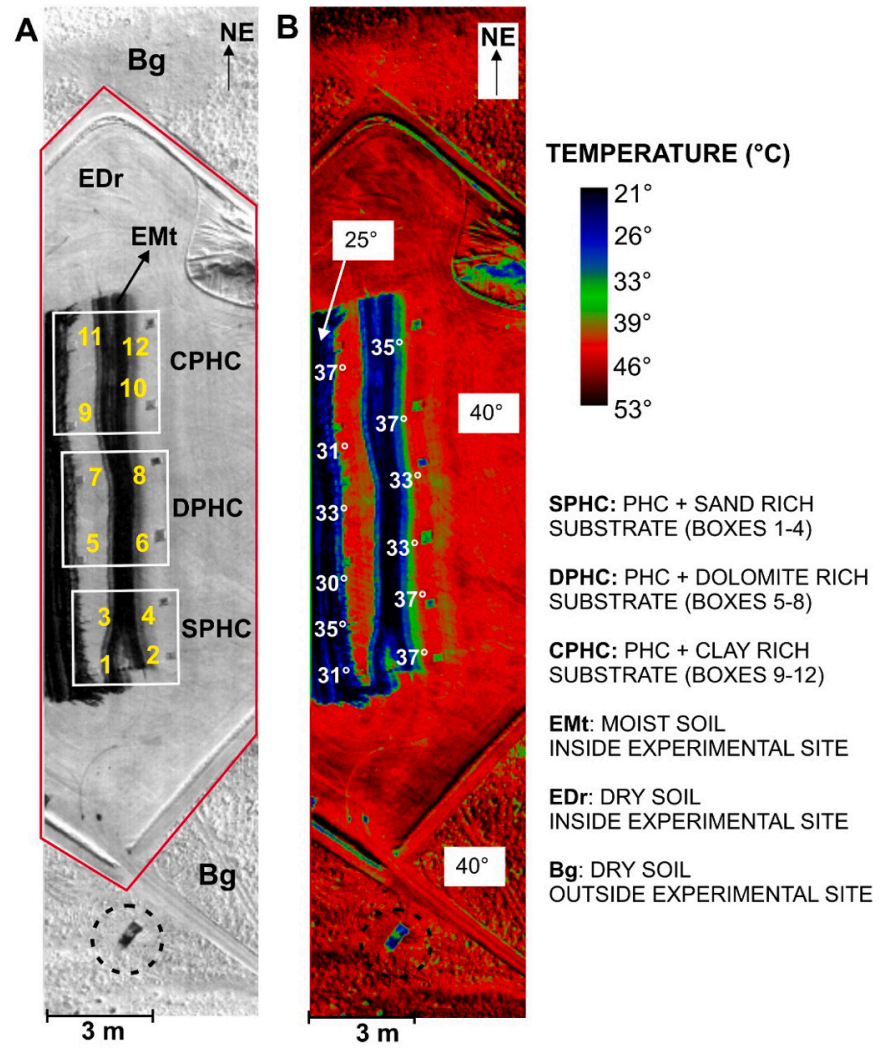

Fig. 9. Temperature estimation. (A) Elements in the study site - see Fig. 2 for more detail. Red lines delimit the area of the experiment. (B) Variation of temperature in the scene. The dotted circle at the bottom of the images marks a car with PHC-based exterior paint. (For interpretation of the references to colour in this figure legend, the reader is referred to the web version of this article.)

the most viable option. Variations in geometry and emissivity in the features of mineral substrates due to the mixture with water and PHC, reported by previous authors (van der Meijde et al. 2013; Pelta and BenDor 2019), were also identified in the DHR signatures of soil-PHC and soil-water mixtures (Fig. 4), van der Meijde et al. (2013) and Pelta and Ben-Dor (2019) achieved good results using regression modeling for the prediction of PHC content in contaminated soils (prepared under controlled lab conditions) based on emissivity values. Furthermore, both authors also recognized changes in absorption features within the 8-10 $\mu \mathrm{m}$ range $\left(1275-1000 \mathrm{~cm}^{-1}\right)$ as valid evidence for the identification of PHC in soil samples.

Here, an increase in the emissivity of silica-associated features (8.8 $\mu \mathrm{m}$ and $9.2 \mu \mathrm{m}$ ) in the spectra of PHC contaminated substrates were identified in the DHR measurements from samples collected in the field (Fig. 5) and in the spectra extracted from the SEBASS image (Fig. 7). The MTMF algorithm separated dry, moist and contaminated substrates in different classes (Fig. 6a). Apart from moist soils that have a characteristic emissivity peak in $10.56 \mu \mathrm{m}$ (Fig. 8b), dry and PHC contaminated soils have similar signatures (Fig. 8a), which indicates that the separation of these classes is based on the variations of emissivity values of main absorption features of mineral substrates.

\subsection{Emissivity and temperature}

Combining variations in emissivity (between 8 and $10 \mu \mathrm{m}$ ) and temperature of mineral substrates seems to be a good indicator for the identification of PHC-soil mixtures. Overall, results demonstrated that temperature and emissivity change depending on the moistening agent covering the mineral substrate (Figs. $10 \mathrm{~b}$ and 10c). Here, an increased emissivity in contaminated substrates $(\sim 94 \%)$ in comparison to moist and dry uncontaminated soils $(\sim 91 \%)$ was identified in laboratory, field and imagery data (Figs. 4, 5 and 8). Similarly, variation between dry $\left(\sim 40{ }^{\circ} \mathrm{C}\right)$, moist $\left(\sim 25^{\circ} \mathrm{C}\right)$ and PHC contaminated $\left(30-37^{\circ} \mathrm{C}\right)$ substrates temperatures were identified in the SEBASS image (Fig. 9). Despite being subtle, these variations allow the separation of dry, moist and contaminated substrates (Figs. 6a and 10a).

Variations in surface temperature and emissivity due to PHC contamination have been reported in previous studies (Nasipuri et al. 2006; Din et al. 2008). George et al. (2010) found that an oil spillage alters the thermal properties of the soil, turning the thermal absorptivity (i.e. ability of the material to absorb heat) of the PHC-soil lower than that of uncontaminated samples. Due to the PHC's lower heat capacity (Leifer et al. 2012), the heat transfer in soil samples covered with PHC is faster than in the uncontaminated surroundings, which implies greater temperature variation in the contaminated soil. In a practical study, Din et al. (2008) monitored surface alterations from the Kuwaiti oil spill (occurred in 1991) with multi-temporal Landsat TM land surface temperature (LST) data, acquired between 1989 and 1998. Temperature anomalies in the sites contaminated with PHC persisted in the images acquired during the post-spill period, demonstrating that changes in the thermal properties of soils associated with PHC remain identifiable for years after the contamination event. However, opposite to the observations reported here, the contaminated surfaces displayed higher temperatures than the surrounding uncontaminated background soil (Din et al. 2008). Here, the PHC contaminants were first exposed during the field experiment, and the images were acquired a short time after the contamination (15 min). Unlike the background soil that was exposed throughout the day, the short exposure of the PHC-soil mixture prior to the airborne survey limited the time for heat transfer. This, summed with the evaporation of PHC volatiles, caused the contaminated soil to have a lower temperature than the background soil at the time the imagery was acquired.

\subsection{NIR-SWIR versus TIR airborne measurements}

Scafutto et al. (2017) used the same MTMF algorithm to classify images acquired in the NIR-SWIR range (ProSpecTIR-VS sensor) during the same field experiment in Casper (see Fig. S3 in the supplementary material). Their results showed that besides the contaminated boxes, hyperspectral data were capable of mapping the roof of cars (i.e. PHCbased paint - Roberts et al. 2012) and contaminated waste at the edge of the experimental site. The contaminated waste was not imaged by the SEBASS instrument, but the car (indicated by a black circle in Fig. 6) is not detected in the TIR data, showing that the intensity of PHC features in the range covered by SEBASS is not strong enough for direct hydrocarbon detection. Furthermore, the non-detection of the PHC-based paint from the cover of the car also indicates that the detection of PHC contaminated areas in the TIR range demands emissivity contrast. Given this finding, an area covered by the TIR data must contain both the contaminated and uncontaminated background soils for successful leakage/seepage detection.

Misclassification between PHC-contaminated sites and vegetation in an advanced stage of senescence (i.e., dry) using NIR-SWIR data has been documented and discussed earlier (Kokaly et al. 2013; Correa Pabón and Souza Filho, 2016; Peterson et al., 2015). Using TIR data, the problem seems to be minimized. Dry vegetation mapped as false positives in the ProSpecTIR NIR-SWIR data by Scafutto et al. (2017) (see Fig. S3 in the supplementary material) was not mapped in the image simultaneously acquired in the TIR range with the SEBASS sensor. Despite the fact that lignin and cellulose display absorption features in the same range covered by SEBASS $(7.5-13.5 \mu \mathrm{m})$, these features (given by ATR and DHR measurements) are too subtle to be resolved in the spectral resolution of the airborne sensor. Since the features related to plant components are too weak to be detected by SEBASS, false-positives anomalies arising from dry vegetation are minimized in the TIR range. 

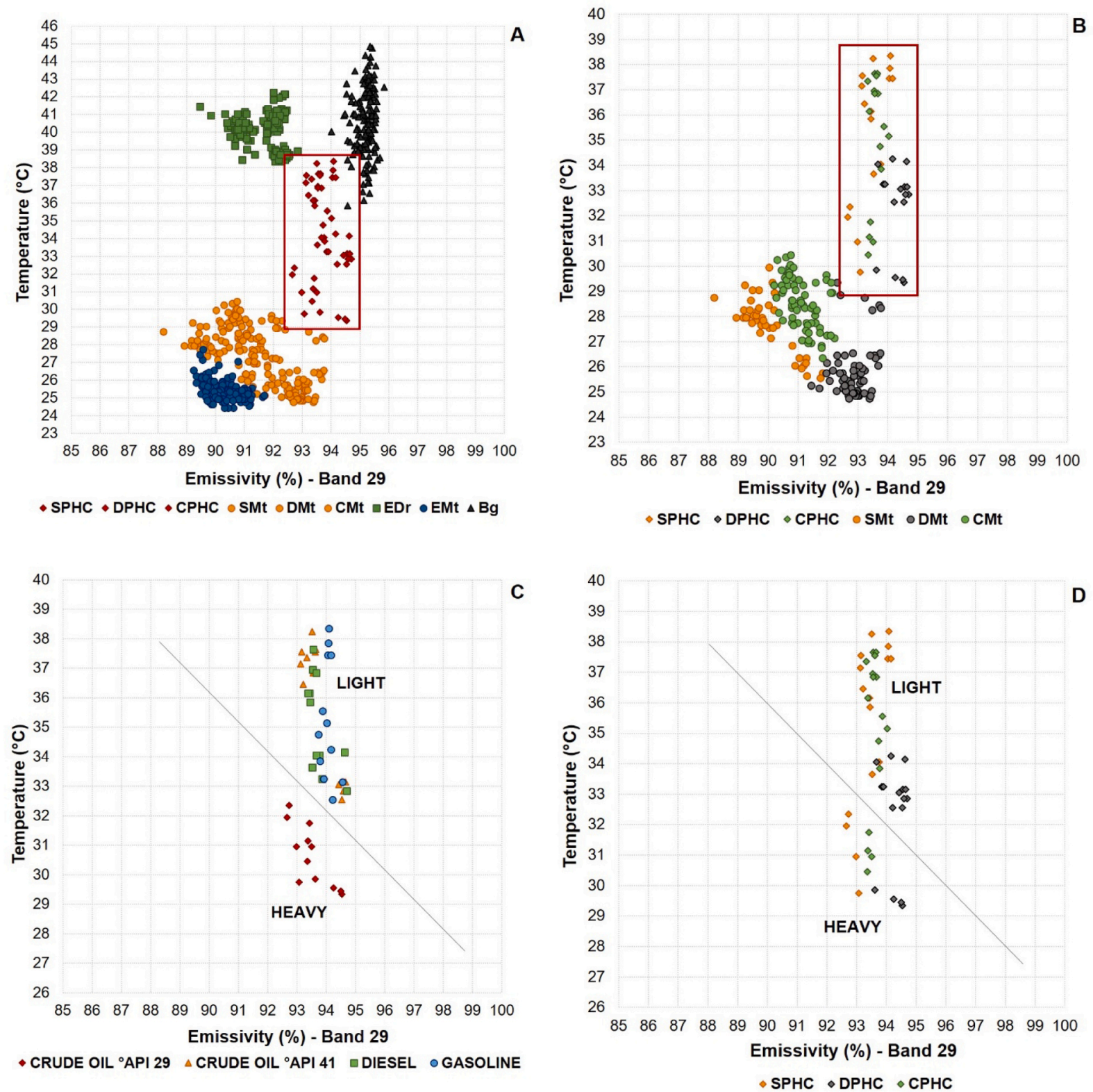

\section{LEGEND}

MINERAL SUBSTRATES CONTAMINATED WITH PHC

MINERAL SUBSTRATES UNCONTAMINATED

UNCONTAMINATED

SPHC: PHC + SAND RICH SUBSTRATE DPHC: PHC + DOLOMITE RICH SUBSTRAT CPHC: PHC + CLAY RICH SUBSTRATE

SMt: LEFTOVERS OF SAND RICH SUBSTRATE Dmt: LEFTOVERS OF DOLOMITE RICH SUBSTRATE Cmt: LEFTOVERS OF CLAY RICH SUBSTRATE
EMt: MOIST SOIL INSIDE EXPERIMENTAL SITE EDr: DRY SOIL INSIDE EXPERIMENTAL SITE Bg: DRY SOIL OUTSIDE EXPERIMENTAL SITE

Fig. 10. Emissivity vs Temperature plots. (A) Comparison between all the components in the scene - see Fig. 2 for more detail. (B) Comparison between moist soil leftovers (uncontaminated) and contaminated mineral substrates. (C) Distribution of contaminated boxes based on PHC contaminants. (D) Distribution of contaminated boxes based on mineral substrate composition. In (A) and (B), the red square highlights PHC contaminated substrates. (For interpretation of the references to colour in this figure legend, the reader is referred to the web version of this article.)

\section{Conclusions}

In this study, the applicability of airborne imaging spectrometers for the mapping of areas contaminated with PHCs was evaluated. A comprehensive analysis of PHC features in the TIR was conducted through ATR (pure materials) and DHR (soil-PHC mixtures from laboratory and field experiments) measurements. Results demonstrated that the subtle absorption features of PHC between 7 and $15 \mu \mathrm{m}$ are masked by strong absorption features from mineral substrates in this range, preventing the direct detection of the contaminant. The information extracted from the SEBASS hyperspectral TIR airborne data confirmed the findings obtained from laboratory experiments; i.e., PHC spectral features could not be identified, with confidence, in the spectral signatures of the classes mapped with the MTMF algorithm. Nevertheless, PHC contaminated substrates could be isolated from the background soil (moist and dry) and moistened mineral substrates (with the same 
composition), based on changes induced in the temperature and emissivity of silica features between 8 and $10 \mu \mathrm{m}$. The liquid (oil or water) covering the grains increases the emissivity and lowers the temperature of the mineral substrate, which allows differentiating dry, moist, and contaminated soil in this range. Boxes contaminated with heavy and light PHCs could also be separated based on temperature variances. However, although we have tried to simulate a real contamination scenario of an oil spill accident, we must also take into consideration that the conditions of the experiment are man-made, and therefore this temperature variation between PHC-contaminated and surrounding soils (dry and moist) can vary in a real scenario. Furthermore, the lower temperature of contaminated sites reported here conflicts with the higher temperature of areas affected by oil spills described in previous studies with temporal analysis. Despite remaining over the years, surface temperature anomalies related to PHC contamination seems to change over time with exposure, and further investigation is needed.

Since TIR data may be used for indirect detection of PHCs through the differences in emissivity and temperature of contaminated and PHCfree sites, the methodology has the potential to be applied using orbital sensors. ASTER (Advanced Spaceborne Thermal Emission and Reflection Radiometer) and the recently released ECOSTRESS (ECOsystem Spaceborne Thermal Radiometer Experiment on Space Station) systems have bands located at wavelengths where variations in silica features induced by PHCs can be identified $(8-10 \mu \mathrm{m})$ and could be evaluated for the indirect detection of PHC-contaminated sites on a larger scale.

\section{Funding}

This work was supported by the São Paulo Research Foundation, Brazil - FAPESP [Grants \#2018/12969-0 and \#2015/19842-7 to R.D. PM.S.] and the Brazilian National Council for Scientific and Technological Development, Brazil - CNPq [Grant \#309712/2017-30 to C.R. S.F].

\section{Declaration of Competing Interest}

None.

\section{Acknowledgement}

The authors would like to especially acknowledge Dr. Beatriz Ribeiro da Luz (USGS) for the measurements of field samples at the USGS laboratory; Kathrin Zweers and MSc. Camilla Marcatelli (Faculty of GeoInformation Science and Earth Observation - ITC) for support and assistance with sample preparation and measurements in the laboratory experiments; Dr. Michael Denk for assistance with the DHR measurements; and Dr. Saied Asadzadeh (UNICAMP) for his valuable review of the paper.

\section{Appendix A. Supplementary data}

Supplementary data to this article can be found online at https://doi. org/10.1016/j.rse.2021.112323.

\section{References}

Asadzadeh, S., de Souza Filho, C.R., 2017. Spectral remote sensing for onshore seepage characterization: A critical overview. Earth Sci. Rev. 168, 48-72.

Asadzadeh, S., Souza Filho, C.R., 2016. Investigating the capability of WorldView-3 superspectral data for direct hydrocarbon detection. Remote Sens. Environ. 173, $162-173$.

Asadzadeh, S., de Souza Filho, C.R., Nanni, M.R., Batezelli, A., 2019. Multi-scale mapping of oil-sands in Anhembi (Brazil) using imaging spectroscopy. Int. J. Appl. Earth Obs. Geoinf. 82, 101894.

Boardman, J.W., Kruse, F.A., 2011. Analysis of imaging spectrometer data using Ndimensional geometry and a mixture-tuned matched filtering approach. IEEE Trans. Geosci. Remote Sens. 49, 4138-4152.

Clark, R.N., 1999. Spectroscopy of rocks and minerals, and principles of spectroscopy. Manual Remote Sens. 3, 2.
Cloutis, E., 1989. Spectral reflectance properties of hydrocarbons: remote-sensing implications. Science(Washington) 245, 165-168.

Correa Pabón, R.E., Souza Filho, C.R., 2016. Spectroscopic characterization of red latosols contaminated by petroleum-hydrocarbon and empirical model to estimate pollutant content and type. Remote Sens. Environ. 175, 323-336.

Correa Pabón, R.E., Souza Filho, C.R., 2019. Crude oil spectral signatures and empirical models to derive API gravity. Fuel 237, 1119-1131.

Din, U.S., Al Dousari, A., Literathy, P., 2008. Evidence of hydrocarbon contamination from the Burgan oil field, Kuwait-interpretations from thermal remote sensing data. J. Environ. Manag. 86, 605-615.

DiStasio Jr., R.J., Resmini, R.G., 2010. Atmospheric compensation of thermal infrared hyperspectral imagery with the emissive empirical line method and the in-scene atmospheric compensation algorithms: a comparison. In: proceedings of International Society for Optics and Photonics (SPIE), p. 7695.

Elvidge, C.D., 1988. Thermal infrared reflectance of dry plant materials: 2.5-20.0 $\mu \mathrm{m}$. Remote Sens. Environ. 26, 265-285.

George, N., Akpabio, G., Udofia, K., 2010. The implication of oil spillage on the thermal properties of soil samples in the Niger delta, southern Nigeria. Archiv. Phys. Res. 1, 64-72.

Green, D., Schodlok, M., 2016. Characterisation of carbonate minerals from hyperspectral TIR scanning using features at 14000 and $11300 \mathrm{~nm}$. Aust. J. Earth Sci. 63, 951-957.

Hecker, C., Hook, S., Meijde, M.V.D., Bakker, W., Werff, H.V.D., Wilbrink, H., Ruitenbeek, F.V., Smeth, B.D., Meer, F.V.D., 2011. Thermal infrared spectrometer for earth science remote sensing applications-instrument modifications and measurement procedures. Sensors 11, 10981.

Hulley, G.C., Duren, R.M., Hopkins, F.M., Hook, S.J., Johnson, W.R., Eng, B.T., Mihaly, J. M., Jovanovic, V.M., Chazanoff, S.L., Staniszewski, Z.K., 2016. High spatial resolution imaging of methane and other trace gases with the airborne hyperspectral thermal emission spectrometer (HyTES). Atmos. Measure. Techn. 9, 2393.

Hunt, G.R., 1980. Electromagnetic radiation: the communication link in remote sensing. Remote Sens. Geol. 5-45.

Kokaly, R.F., Couvillion, B.R., Holloway, J.M., Roberts, D.A., Ustin, S.L., Peterson, S.H., Khanna, S., Piazza, S.C., 2013. Spectroscopic remote sensing of the distribution and persistence of oil from the Deepwater horizon spill in Barataria Bay marshes. Remote Sens. Environ. 129, 210-230.

Lammoglia, T., Souza Filho, C.R., 2011. Spectroscopic characterization of oils yielded from Brazilian offshore basins: potential applications of remote sensing. Remote Sens. Environ. 115, 2525-2535.

Leifer, I., Lehr, W.J., Simecek-Beatty, D., Bradley, E., Clark, R., Dennison, P., Hu, Y., Matheson, S., Jones, C.E., Holt, B., Reif, M., Roberts, D.A., Svejkovsky, J.,

Swayze, G., Wozencraft, J., 2012. State of the art satellite and airborne marine oil spill remote sensing: application to the BP Deepwater horizon oil spill. Remote Sens. Environ. 124, 185-209.

Li, Z.L., Becker, F., Stoll, M.P., Wan, Z., 1999. Evaluation of six methods for extracting relative emissivity spectra from thermal infrared images. Remote Sens. Environ. 69 (3), 197-214.

Luz, B.R., 2006. Attenuated total reflectance spectroscopy of plant leaves: a tool for ecological and botanical studies. New Phytol. 172, 305-318.

Luz, B.R., Crowley, J.K., 2007. Spectral reflectance and emissivity features of broad leaf plants: prospects for remote sensing in the thermal infrared $(8.0-14.0 \mu \mathrm{m})$. Remote Sens. Environ. 109, 393-405.

McKendry, P., 2002. Energy production from biomass (part 1): overview of biomass. Bioresour. Technol. 83, 37-46.

van der Meijde, M., Knox, N.M., Cundill, S.L., Noomen, M.F., van der Werff, H.M.A., Hecker, C., 2013. Detection of hydrocarbons in clay soils: A laboratory experiment using spectroscopy in the mid- and thermal infrared. Int. J. Appl. Earth Obs. Geoinf. 23, 384-388.

Nasipuri, P., Majumdar, T., Mitra, D., 2006. Study of high-resolution thermal inertia over western India oil fields using ASTER data. Acta Astron. 58, 270-278.

Nicodemus, F.E., 1965. Directional reflectance and emissivity of an opaque surface. Appl. Opt. 4, 767-775.

Pelta, R., Ben-Dor, E., 2019. An exploratory study on the effect of petroleum hydrocarbon on soils using hyperspectral longwave infrared imagery. Remote Sens. 11, 569.

Peterson, S.H., Roberts, D.A., Beland, M., Kokaly, R.F., Ustin, S.L., 2015. Oil detection in the coastal marshes of Louisiana using MESMA applied to band subsets of AVIRIS data. Remote Sens. Environ. 159, 222-231.

Roberts, D.A., Quattrochi, D.A., Hulley, G.C., Hook, S.J., Green, R.O., 2012. Synergies between VSWIR and TIR data for the urban environment: an evaluation of the potential for the hyperspectral infrared imager (HyspIRI) decadal survey mission. Remote Sens. Environ. 117, 83-101.

Salisbury, J.W., D'Aria, D.M., 1994. Emissivity of terrestrial materials in the 3-5 $\mu \mathrm{m}$. atmospheric window. Remote Sens. Environ. 47, 345-361.

Sanches, I.D., Souza Filho, C.R., Magalhães, L.A., Quitério, G.C.M., Alves, M.N., Oliveira, W.J., 2013. Assessing the impact of hydrocarbon leakages on vegetation using reflectance spectroscopy. ISPRS J. Photogramm. Remote Sens. 78, 85-101.

Scafutto, R., Souza Filho, C., 2018. Detection of methane plumes using airborne Midwave infrared (3-5 $\mu \mathrm{m})$ hyperspectral data. Remote Sens. 10, 1237.

Scafutto, R.D.P.M., Souza Filho, C.R.D., 2016. Quantitative characterization of crude oils and fuels in mineral substrates using reflectance spectroscopy: implications for remote sensing. Int. J. Appl. Earth Obs. Geoinf. 50, 221-242.

Scafutto, R.D.P.M., de Souza Filho, C.R., de Oliveira, W.J., 2017. Hyperspectral remote sensing detection of petroleum hydrocarbons in mixtures with mineral substrates: implications for onshore exploration and monitoring. ISPRS J. Photogramm. Remote Sens. 128, 146-157.

Schumacher, D., 1996. Hydrocarbon-Induced Alteration of Soils and Sediments. 
Silverstein, R.M., Bassler, G.C., 1962. Spectrometric identification of organic compounds. J. Chem. Educ. 39, 546.

Spragg, R., 2017. IR Spectroscopy Sample Preparation Methods.

Stuart, B., 2004. Infrared Spectroscopy: Fundamental and Applications. John Wiley \& Sons, Ltd.

Tratt, D.M., Buckland, K.N., Hall, J.L., Johnson, P.D., Keim, E.R., Leifer, I., Westberg, K., Young, S.J., 2014. Airborne visualization and quantification of discrete methane sources in the environment. Remote Sens. Environ. 154, 74-88.

Van der Meer, F., Van Dijk, P., Van Der Werff, H., Yang, H., 2002. Remote sensing and petroleum seepage: a review and case study. Terra Nova 14, 1-17.
Webster, G.T., Soriano-Disla, J.M., Kirk, J., Janik, L.J., Forrester, S.T., McLaughlin, M.J., Stewart, R.J., 2016. Rapid prediction of total petroleum hydrocarbons in soil using a hand-held mid-infrared field instrument. Talanta 160, 410-416.

Yitagesu, F.A., Van der Meer, F., Van der Werff, H., Hecker, C., 2011. Spectral characteristics of clay minerals in the $2.5-14 \mu \mathrm{m}$ wavelength region. Appl. Clay Sci. $53,581-591$.

Young, S., 1998. In scene atmospheric compensation: Application to SEBASS data collected at the ARM site. Part II. In: Aerospace Report ATR-99 (8407), Part II. 